\title{
Cytomorphologic Evaluation of the Thin Prep for Fine Needle Aspiration of the Fresh Thyroidectomy Specimens
}

Yılmaz Baş*, Havva Hande Keser and Behice Hande Erenler

Department of Pathology, Hitit University Education and Research Hospital, Çorum, Turkey

\section{Abstract}

Objective: This study aimed to compare cytomorphology of ThinPrep Papanicolaou (TP PAP) method with the macroscopic-microscopic findings of the nodules on fresh thyroidectomy specimens.

Study Design: A total of 75 thyroid surgical specimens were included in our study. Fine Needle Aspiration Biopsy (FNAB) of specimens was performed by a pathologist. Aspirate was taken into TP liquid and stained with PAP. We defined cytological findings, compatible with macroscopic-microscopic findings.

Results: In cytologic evaluation 108 nodules were diagnosed benign, while 18 nodules were malignant and 2 cystic nodules were insufficient. Cytological diagnosis was compatible with histologically benign a total of 110 nodules, and 18 malignant nodules. Nuclear groove/irregular nuclear membrane, nuclear overlap/crowding, nuclear enlargement, nuclear pseudoinclusion, pale/fine chromatin are determined as statistically significant cytological parameters in malignant cases.

Conclusion: FNAB and the histo-morphological and TP PAP cytological slides were evaluated by pathologists at every stage of biopsy process. It is clearly understood how important it is to obtain adequate cells from the benign or malignant thyroid nodules with this method. Although controversial opinions among the cytopathologists regarding the association using TP method are present, in this study we revealed that TP method is easy to use for FNAB.

Keywords: Thyroid; Fine needle aspirasyon; ThinPrep; Cytomorphology; Histomorphology

\section{Introduction}

Fine needle aspiration biopsy (FNAB) has been used since the 1950s, and is one of the most effective methods in the diagnosis. It has provided greatest clinical use in reducing the rate of unnecessary thyroidectomies [1]. With the use of FNAB, it gave direction for making clinical decisions and it is considered a diagnostic milestone for thyroid nodules for many years [2]. ThinPrep Papanicolaou (TPPAP) method has gained popularity as a preparation technique for FNAB, which has been approved by the Federal Drug Administration (FDA) for use in preparing non-gynaecologic cytology and fine needle aspiration materials in $1991[3,4]$.

\section{Materials and Methods}

A total of 75 thyroid surgical specimens were obtained from Hitit University Training and Research Hospital, between June the 1st, 2014 and April the 10th, 2016. Patient's age ranged from 17-73 years. Fiftyeight female (77.3\%) and 17 male $(22.7 \%)$, with a mean age of 43.75 years (range 17-73, median 34 years) were enrolled in the study. A total of 128 nodules in 75 specimens included study. The Ethics Committee of the Faculty of Medicine, University of Hitit, approved this study (No. 014/16).

Eighteen nodules in 18 thyroidectomy specimens histologically diagnosed as malign which 5 of $18(27.7 \%)$ were male and 13 of 18 (72.2\%) were female, while 12 of 57 (21.1\%) were male and 45 of 57 (78.9\%) were female. Nodules smaller than $1 \mathrm{~cm}$ and nodules with impaired integrity were excluded. Diameter of the largest malign nodule was $8.0 \mathrm{~cm}$ and the smallest nodule was $1.2 \mathrm{~cm}$ ( mean $3.25 \mathrm{~cm}$ ), while the largest benign nodule diameter was $7.0 \mathrm{~cm}$ and the benign smallest nodule diameter was $1.1 \mathrm{~cm}$ (mean $3.5 \mathrm{~cm}$ ) (Table 1).

Firstly, pathologist performed FNAB on the fresh thyroidectomy and after that placed the specimen in $10 \%$ formalin for fixation (Figure 1).

Two experienced pathologists examined the thyroidectomy specimens, and evaluated the nodules. They photographed and gave codes to each nodule, then performed FNAB to selected nodules. After FNAB, at least two samples were taken for routine histology. Only medullary carcinoma (MC) couldn't be photographed. 21-23 gauge needles were used for aspiration. The aspiration material was transferred into tightly sealed specimen cups containing $10 \mathrm{cc}$ fixative CytoLyt Solution (Hologic Co. Marlbourough, Mass, USA) and needle were left in the liquid. Sample was centrifuged for $10 \mathrm{~min}$ at $600 \mathrm{rpm}$. After discarding the supernatant, bottom material transferred in to plastic tubes containing cyto-preservative solution (PreservCyt ${ }^{\oplus}$; Hologic Co). The cells were fixed by PreservCyt ${ }^{\circ}$ solution throughout $30 \mathrm{~min}$. One

\begin{tabular}{|l|l|l|l|}
\hline & Malignant $\mathbf{( n = 1 8 )}$ & Benign $(\mathbf{n = 5 7})$ & P-value \\
\hline Female & $13(72.2 \%)$ & $45(78.9 \%)$ & 0.552 \\
\hline Male & $5(27.7 \%)$ & $12(21.0 \%)$ & \\
\hline Age, mean (SD) & 48.72 years (16.32) & 48.75 years (14.14) & 0.994 \\
\hline $\begin{array}{l}\text { Nodule size, median } \\
\text { (range) }\end{array}$ & $3.25 \mathrm{~cm} \mathrm{(1.2-8.0)}$ & $3.5 \mathrm{~cm} \mathrm{(1.1-7.0)}$ & 0.773 \\
\hline
\end{tabular}

Table 1: Clinical characteristics of malignant and benign nodules.

*Corresponding author: Yılmaz Baş, Department of Pathology, Hitit University Çorum Education and Research Hospital, Çorum, Turkey, Tel: +0905336437016 Fax:+0903642230300; E-mail: yilbas@yahoo.com

Received December 13, 2016; Accepted March 15, 2017; Published March 25 , 2017

Citation: Baş Y, Keser HH, Erenler BH (2017) Cytomorphologic Evaluation of the Thin Prep for Fine Needle Aspiration of the Fresh Thyroidectomy Specimens. J Cytol Histol 8: 445. doi: 10.4172/2157-7099.1000445

Copyright: ( 2017 Baş Y, et al. This is an open-access article distributed under the terms of the Creative Commons Attribution License, which permits unrestricted use, distribution, and reproduction in any medium, provided the original author and source are credited. 
Citation: Baş Y, Keser HH, Erenler BH (2017) Cytomorphologic Evaluation of the Thin Prep for Fine Needle Aspiration of the Fresh Thyroidectomy Specimens. J Cytol Histol 8: 445. doi: 10.4172/2157-7099.1000445

Page 2 of 7

slide was prepared from material by ThinPrep 2000 Automated Slide Technique [1] and they were stained by Papanicolaou method.

After aspiration material put into cytopreservative solution, solution stored at 8 degrees and TP-PAP stain was performed for at least one week.

Cytological diagnoses were given by using diagnostic categories recommended by Bethesda System for Reporting Thyroid Cytopathology [5]. Table 2 shows main criteria used for cytomorphological evaluation of TP-PAP [3-7].

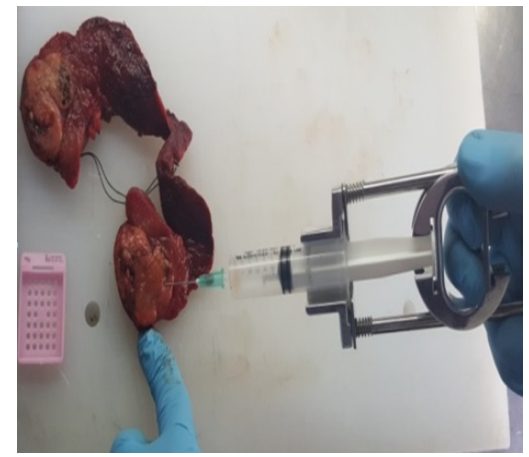

Figure 1: Fine needle aspiration biopsy of nodules on the fresh thyroidectomy.
One pathologist evaluated slides according to the criteria's of Table 2. The cells seen at the peripheral rim of slides was not taken into account. The study was not blinded. We defined specimens as adequate by the presence of at least six groups of cells with a minimum number of well-visualised ten cells in each group $[5,6]$. Table 3 shows the rates of cytological characteristics in malignant and benign lesions in each TP-PAP slide according to criteria in references 3, 6 and 21.

The cytological diagnosis was compared with the histomorphological diagnosis given by the 4 micron-thick sections stained with haematoxylin and eosin (HE). The sections were examined under a Nikon Eclipse Ci model microscope and scanned 100 selected areas rich of cells for the calculated numerical rate shown on Table 3 . Finally, the macroscopic findings were compared with cytological and histological findings of the same nodule.

Statistical analysis was performed by Statistical Package for the Social Sciences (SPSS) 20.0 software package. Numerical variables were summarized by Mean (SD) if normally distributed or by Median (range) if not normally distributed. Numerical variables were compared across the malignant and benign groups by the $t$ test (normally distributed) or the Wilcoxon rank sum test (not normally distributed). Binary presence or absence of the variables were summarized by frequency (\%) and were compared across the groups by the Chi-Square (all expected

\begin{tabular}{|c|c|}
\hline Cellularity & No cell (cystic), few cells (cystic/fibrotic nodules), competent cells, a large number of cells. \\
\hline Cellular distribution & $\begin{array}{l}\text { Single-layer, double-layer, multi-layer, cohesive clusters syncytial trabecular pattern, and true fibrovascular core group, papillary } \\
\text { structures groups, crowded cell clusters, overlap, peripheral palisading on the outer contour of the cell groups, uniform appearance } \\
\text { of the nucleus, papillary similar formations of structures (pseudopapillary without peripheral palisade), protected polarity, equally } \\
\text { distribution molding. }\end{array}$ \\
\hline Microfollicular structure & $\begin{array}{l}\text { Polymorphic, monomorphic, multilayer mikrofollicular organization, double layer without atypia mikrofollicular alignment, protected } \\
\text { polarity (nucleus are equal distance alignment). }\end{array}$ \\
\hline Macrofollicular structure & Protected polarity (nucleus are equal distance alignment). \\
\hline Cell cytomorphology & Follicular, Hurthle cells, spindle, plasmacytoid, tall cells, stromal cells. \\
\hline Cytoplasm & Wide, narrow, fine granules, vacuoles, foamy, septal, clear debris loaded \\
\hline Structure of caryolemma & Regular, partly irregular, completely irregular \\
\hline Nucleus morphology & $\begin{array}{l}\text { Regular, small uniform, anisonucleosis mild to market, pleomorphic, overlap, oval, longitudinal nuclear groove, intranuclear } \\
\text { cytoplasmic inclusions }\end{array}$ \\
\hline Chromatin & $\begin{array}{l}\text { Clear, uniform fine granular (powdery chromatin), coarse granular, rarely prominent nucleolus, prominent eosinophilic eccentric } \\
\text { nucleolus. }\end{array}$ \\
\hline Colloid & $\begin{array}{l}\text { Present, absent, cracked dry earth, thin flowing, granular aggregates, dense form of drops, tissue paper collections, droplets, } \\
\text { spherules, oval-shaped, chewing gum-like }\end{array}$ \\
\hline İnlammatory cells & Lymphocytes, plasma cells, histiocytes, macrophages, multinucleated giant cells \\
\hline Psammoma bodies & Yes, no, concentrated dense lamellar style deposit \\
\hline Amyloid & Yes, no, thin dense drop shape, thin deposit \\
\hline
\end{tabular}

Table 2: Rates of cyctological characteristics in malignant and benign lesions in each TP-PAP slide. $(P=0.00<0.05),\left({ }^{*}\right.$ statistically significant).

\begin{tabular}{|c|c|c|c|}
\hline Feature present & Malign $(n=18) \% 14.1$ & Benign $(n=110) \% 85.9$ & P-value \\
\hline Mono-layer cluster & 28 & 44.6 & 0.373 \\
\hline Cohesive agregate & 94.2 & 54.8 & 0.14 \\
\hline Microfollicular & 36.6 & 64.9 & 0.278 \\
\hline Macrofollicular & 22.4 & 12.6 & 0.365 \\
\hline Nuclear groove/irregular nuclear membrane & 34,8 & 10.2 & *0.027 \\
\hline Nuclear overlap/crowding & 72.4 & 13.7 & $*<0.01$ \\
\hline Nuclear enlargement & 76.2 & 31.5 & *0.025 \\
\hline Nuclear pseudoinclusion & 14.9 & 1.2 & $*<0.01$ \\
\hline Pale/fine chromatin & 33.5 & 8.7 & ${ }^{*}<0.018$ \\
\hline Hurthle cells & 34.3 & 34.6 & 0.944 \\
\hline Colloid & 38.7 & 74.2 & 0.16 \\
\hline Macrofague & 6.6 & 40.4 & *0.029 \\
\hline
\end{tabular}

Table 3: Rates of cyctological characteristics in malignant and benign lesions in each TP-PAP slide. $(P=0.00<0.05),\left({ }^{*}\right.$ statistically significant). 
Citation: Baş Y, Keser HH, Erenler BH (2017) Cytomorphologic Evaluation of the Thin Prep for Fine Needle Aspiration of the Fresh Thyroidectomy Specimens. J Cytol Histol 8: 445. doi: 10.4172/2157-7099.1000445

cell counts in the cross-tabulation table were $>5$ ) or Fisher exact test (any expected cell count $<5$ ).

\section{Results}

Cytological diagnosis of 18 of the nodules were malignant $(14.1 \%)$ and 108 of the nodules were benign (84.4\%). There were 2 (1.6\%) cystic nodules cytological diagnosed as inadequate which were benign HE stained sections. Seven (5.5\%) slides were diagnosed thyroiditis. On histological sections, 6 of $110(4.7 \%)$ benign nodules were diagnosed as follicular adenoma (FA). $14(10.9 \%)$ of malignant nodules were papillary thyroid carcinoma (PTC), 2 (1.6\%) were thyroid follicular carcinoma (FC), 1 (0.8\%) was differential carcinoma and $1(0.8 \%)$ was MC.

Benign cases compared with malignant cases showed no statistically significant difference according to age, gender or nodules sizes ( $\mathrm{p}>$ 0.05) (Table 1).

On TP-PAP slides of benign nodules, mono-layered cell clusters with preserved polarization and micro-follicular arrangement were seen. Colloid was observed in a granular structure, or like cracked dry earth or tissue paper (Figure 2). The nuclei had rounded shape with uniform and thin chromatin pattern. The nuclear membrane was regular and micronucleus was often observed. In some TP-PAP slides, debris laden macrophages were also seen.

Micro-follicular cell clusters were remarkable on slides of cases with thyroiditis. Single or mono-layered clusters of Hurtle cells with large, dense granular cytoplasm were accompanied by lymphocytes. The dense droplet colloid was scanty.

Follicular adenomas TP-PAP slides were cellular with monomorphic pattern of mono or double layered micro-follicular groups and overlapping clusters (Figures 3 and 4). The cells had round-shaped nuclei with coarse chromatin and prominent nucleolus. Nuclear polymorphism and atypical were not remarkable. The scanty dense colloid observed as spherules, droplets or within micro-follicles.

We determined benign and malignant nodules rates according to

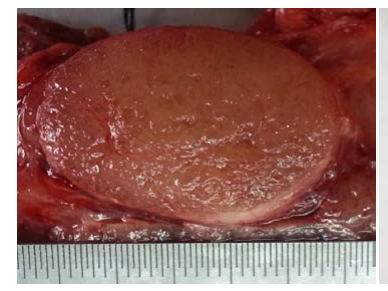

(a)

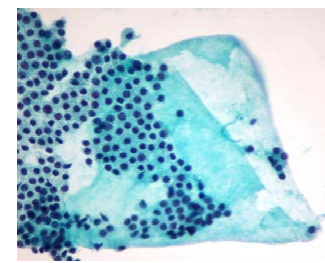

(c)

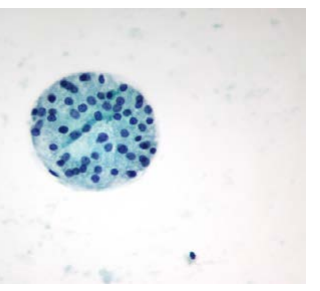

(b)

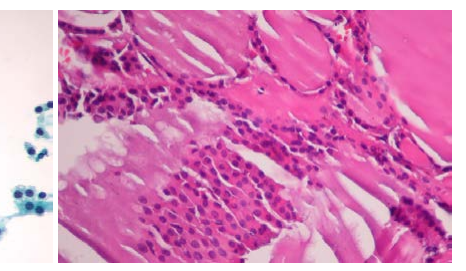

(d)
Figure 2: Benign colloidal nodules. (a) Macroscopic encapsulated, homogeneous, shiny, colloid-rich solid nodules; (b) Discohesive macrofollicule (PAP, x400); (c) A single layer of follicular epithelial cell cluster, with preserved polarisation and thin colloid (tissue paper collection) PA, x200); (d) Histological appearance of follicular epithelial cells (HE, x200). There is striking similarity between figure $\mathrm{c}$ and $\mathrm{d}$.

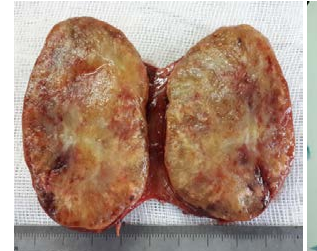

(a)

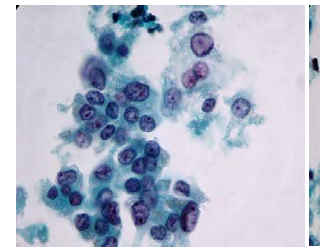

(d)

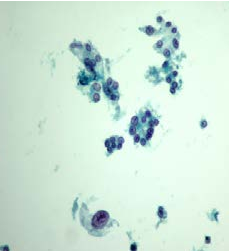

(b)

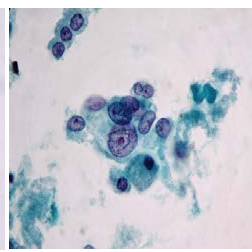

(e)

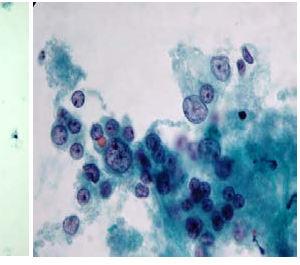

(c)
Figure 3: Follicular adenoma. (a) Macroscopy of a solid nodule with thin capsule, haemorrhage and fibrotic degeneration in some areas; (b) Microfollicullar and isolated distribution of follicular epithelial cells (PAP, x200); (c-e) Anisocytosis of follicular epithelial cells. Nuclear hole appearance aroused the suspicion of pseudoinclusions. Nuclear coarse granular chromatin and prominent nucleolus (PAP, x1000, x1000, x1000); (f) Interstitial edema, hyalinisation and the large nuclei of follicular epithelial cells are remarkable (HE, x400).

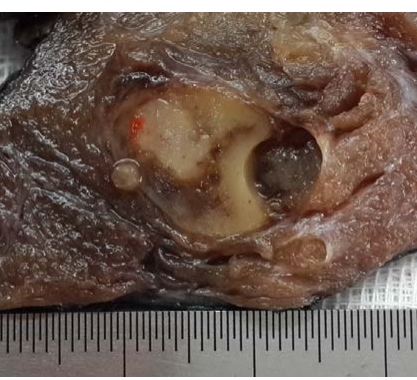

(a)

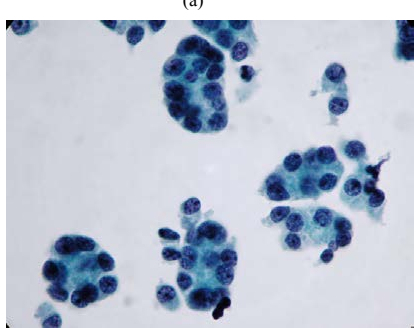

(c)

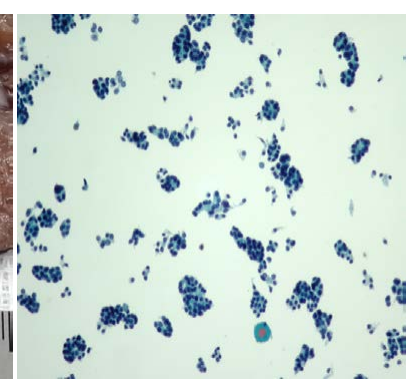

(b)

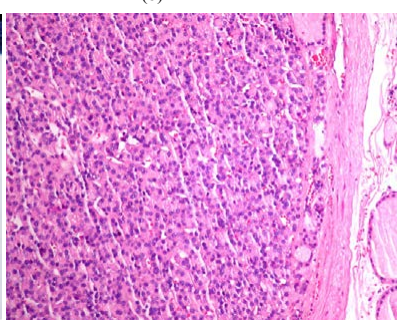

(d)
Figure 4: Follicular adenoma. (a) Macroscopically encapsulated and cystic, light brown nodule; (b-d) Microfollicular arrangement of uniform follicular epithelial cells with coarse granular nuclear chromatin and scanty dense colloid (PAP, orginal magnification x200, x1000) (HE, x200).

main criteria's in Table 3 and also P values were statistically significant for 5 parameters in malignant cases (nuclear groove/irregular nuclear membrane, nuclear overlap/crowding, nuclear enlargement, nuclear pseudo inclusion and faded/thin chromatin) (Figures 5 and 6).

In the Hurtle cell neoplasia, monomorphic and syncytial cell sheets, groups and single Hurtle cells were seen. These cells showed mild anisocytosis, sometimes had prominent nucleolus and intranuclear cytoplasmic inclusions were rarely observed while colloid not observed. Atypical cells groups with double layer, remarkable micro follicular pattern, pseudo papillary without peripheral palisade were common among the slides considered as malignant. 


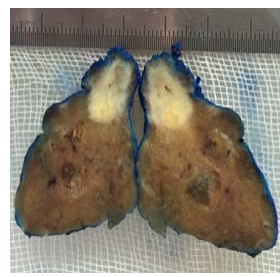

(a)

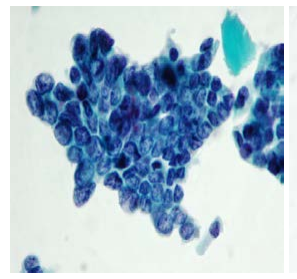

(d)

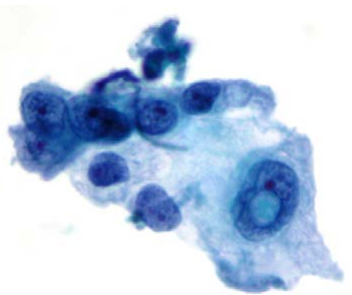

(Inset)

Figure 5: Papillary thyroid carsinoma, classical variant. (a) Uncapsulated, irregular, cream-colored solid mass; (b-d) Loss of polarity, single and double layer of cohesive clusters with irregular edges, syncytial groups, overlap forming epithelial cells, groove; b and c in small, dark closed chromatin pattern, protected polarity of benign follicular epithelial cell clusters (top right clusters); Inset: Pseudoinclusions (PAP, x400, x1000, x1000, x1000); (e) Colloid droplet (PAP, x100); (f) Fibrovascular core with a typical papillary structures (HE, $\mathrm{x} 400)$

Micro-follicles, cohesive groups of cells with loss of polarity, pseudo inclusions and groove were seen on FC slides (Figure 7).

On UC slides, isolated scattered spindle cytoplasm, irregular nucleolemma, pleomorphic, coarse granular chromatin patterns, noticeably nucleoli, appearance of malignant cells in sarcomatoid and necrobiotic material and isolated tumour cell clusters with loss of polarity were seen (Figure 8).

And on MC slides, atypical cell groups of plasmacytoid cells with eccentric located salt and pepper sign of chromatin pattern , pleomorphic nuclei were seen (Figure 9).

Nodules which diagnosed malignant were irregular lining, creamcolour, solid structure and rigid. Some of them had spread outside the capsule and necrosis. TP slide had clusters with cellular and loss of polarity. Cluster environment was irregular and fringed structure compared to the benign groups. There were papillae formations with central fibro vascular core.

\section{Discussion}

Thin Prep Papanicolaou method provides both easy to clinical use and transport. The best quality in specimens may be obtained because blood and debris may be avoided from the floor and it is less-invasive [8]. It allows protection of nuclear details and decreased scan times with cytopathology, immunohistochemistry and molecular diagnostics [3,911]. In some cases, the cell block has importance because of its pivotal role in diagnosis of preparation samples [11]. Uniform spreading of the
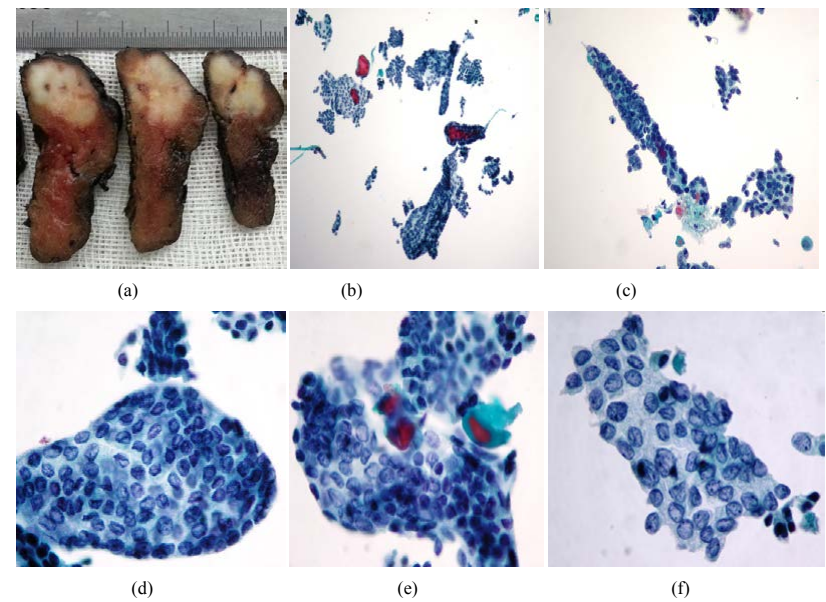

(d)

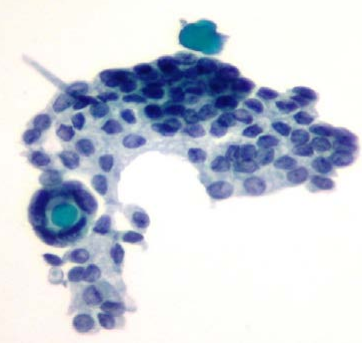

$(\mathrm{g})$

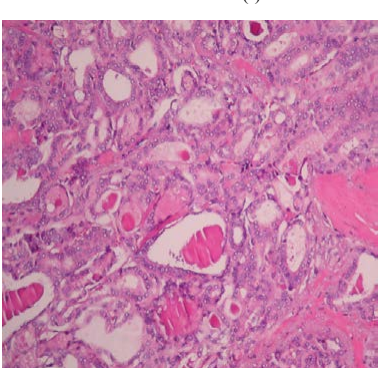

(h)
Figure 6: Papillary thyroid carcinoma, follicular variant. (a) Uncapsulated, irregular, cream-colored solid mass; (b-g) single and double layer with loss of polarity, irregular border clusters, overlap, macrofollicular, microfollicular and papillary structures; (e and f) pseudoinclusions and groove samples; $(f)$ Fine chromatin and prominent eosinophilic nucleoli (PAP, x200, x400, x1000 $\mathrm{x} 1000, x 1000, x 1000)$; (h) Different diameters of follicular variant of PTC (HE, $\mathrm{x} 200)$.

cells was obtained in an area of $20 \mathrm{~mm}$. When presence of inadequate conditions, solution of the remaining was prepared once again and it provided results in satisfactory adequate rate [4].

At the same time, this method has disadvantages such as decreased values of diagnostic stromal features, impaired epithelial-stromal connection, peripheral compression artifact and inadequate diagnosis rate because of close to the conventional smear $[3,12]$.

Peripheral pressure of artifact potentially affects the cell morphology in TP smears. An increased cytoplasm and nucleus size can be confused with atypical cells. In addition, nuclei can be seen as indeterminate and hyper chromatic [12]. For this reason, we excluded peripheral rim of cells.

In a study by Kim et al. [9], it was reported that, when aspirated material taken into TP solution and stored at room temperature or $-80^{\circ}$ for 1-12 months, any differences were not observed in time dependence of the nuclear dimensions rate. In our study, aspirated material was stored at $8^{\circ}$ and in one week, it was studied and stained by PAP. Deterioration in cellular morphology was not observed.

It was found in one study that inadequacy rates of liquid based cytology were $24 \%, 33 \%$ and $32 \%$ [4].

In our study, non-diagnostic and possibility of inadequate slide were eliminated by making aspiration biopsy of nodule in thyroidectomy specimens. By this way, accuracy of cytomorphologic criteria's was evaluated by histological morphology. All smears can be 
Citation: Baş Y, Keser HH, Erenler BH (2017) Cytomorphologic Evaluation of the Thin Prep for Fine Needle Aspiration of the Fresh Thyroidectomy Specimens. J Cytol Histol 8: 445. doi: 10.4172/2157-7099.1000445

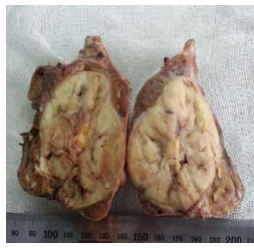

(a)
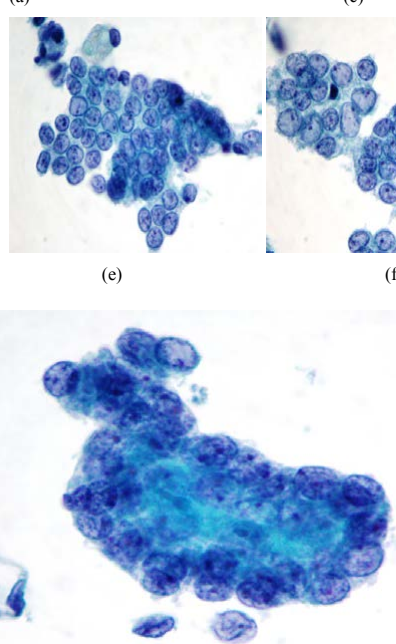

(Inset)

Figure 7: Follicular Carcinoma. (a) Thin capsule, cream-colored, solid nodules (b-f) Microfollicules, groups of cells with loss of polarity; (d-f) pseudoinclusions and groove; Inset: A cohesive macrofollicule and overlap structure (PAP, $\mathrm{x} 200, \mathrm{x} 400, \mathrm{x} 1000, \mathrm{x} 1000, \mathrm{x} 1000, \mathrm{x} 1000, \mathrm{x} 1000) ;(\mathrm{g})$ Immunohistochemical examination of the CD 31 and the focus of perivascular invasion (x200); $(h)$ Capsule invasion (HE, x200); (i) Clear cell, scarce colloid micro-follicules structures $(\mathrm{HE}, \mathrm{x} 400)$.

clearly evaluated cytoplasm, nuclear size, nuclear membrane integrity, clarity of the nucleus and chromatin pattern through TP-PAP method. In a study by Penin et al. [7], it was considered that this might be an alternative method for seeing the greater number of cells.

Colloid is seen as cracked dry earth, granular deposits and tissue paper collections forms in TP slides [3,11]. In our study, the presence or absence of colloid is similar to findings of Duncan et al. [3]. It was easily determined because it has either middle-eosinophilic, periphery of the blue ovoid or round in shape of aggregates or diffuse, mottled, blue-green and light blue coloured layer. Immuno-histochemical use of thyroglobulin is also occasionally helpful to distinguish the cause of miscible cases with fibrin.

In our study, in benign follicular lesions, well-organised, colloidcontaining micro-follicles instead of macro-follicles were also observed [13]. Macro-follicles were single-layered and in different dimensions. Honeycomb appearance and polarity-preserved cells were an important findings of benign lesions and haemorrhagic findings and macrophages were accompanying factors. Liquid colloid was typically seen at microfollicle, in addition to this, there were micro-follicles with droplet of central dense colloids. Nuclei were uniform, small diameter, course granular chromatin or dark-coloured. We determined some lesions were irregular-circumscribed, single layer cluster, nuclear anisocytosis, nuclear coarsening and clarity, hyper-chromatic and groove like of nuclear membrane tortuosity cells (Figure 3). Disorganized and crowded groups, crowded micro-follicular and trabecular patterns were typically seen in Hurtle cell lesions or degenerative changes in nodules. Clinical and radiologic correlation should be kept in mind in order to

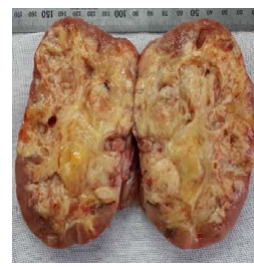

(a)

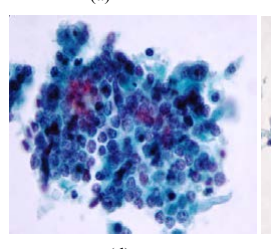

(d)

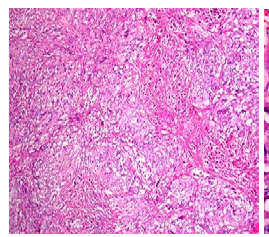

(g)
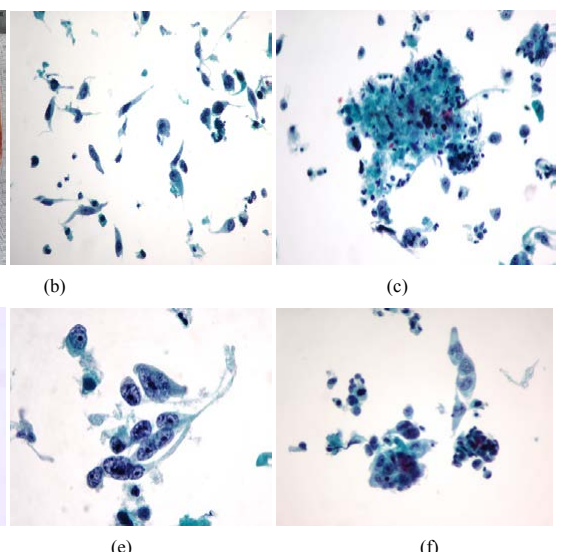

(f)

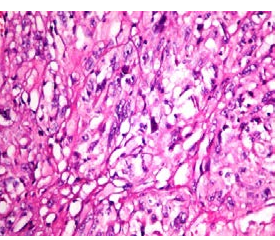

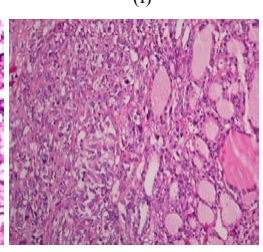

Figure 8: Undifferentiated (anaplastic) carcinoma. (a) Cream-white, heterogeneous solid mass with large areas of necrosis, covered the entire lobe and showed macroscopic extension beyond the thyroid capsule; (bf) Sarcomatoid appearance of malignant cells (isolated scattered spindle cytoplasm, irregular nucleolemma, pleomorphism, coarse granular chromatin pattern, noticeably nucleoli) (PAP, x400, x100, x400); (c) Necrobiotic material and isolated tumor cells (PAP, x400); (d) Loss of polarity, cohesive cells clusters (PAP, x400); (g-i), Eliminated the normal thyroid tissue, included coagulative necrosis areas, noticeable pleomorphic, sarcomatoid appearance of undifferentiated atypical cell carcinoma areas (HE, x100, x400, x200).

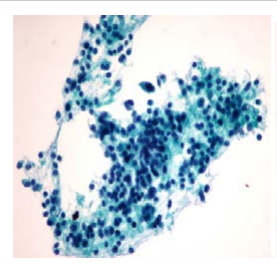

(a)

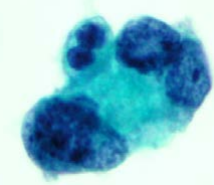

(d)

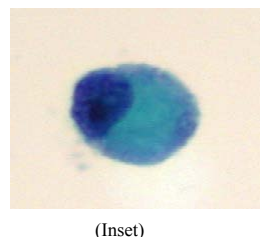

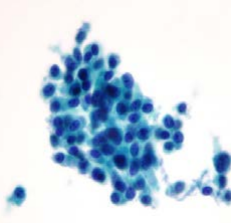

(b)

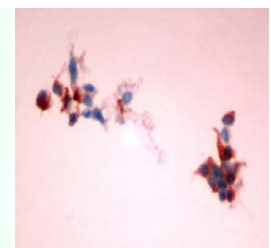

(e)

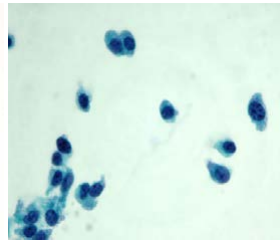

(c)

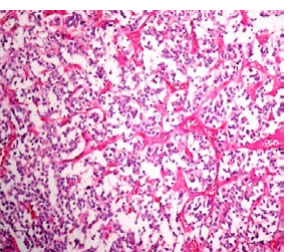

Figure 9: Medullary thyroid carcinoma. (a) Single layer, syncytial clusters in fibrillar material on the ground (PAP, x200); (b) Irregular borders, dishezive cells clusters (PAP $\times 400$ ); (c) Appearance of plasmacytoid isolated scatter cells; Inset: Eccentric located nucleus with plasmacytoid appearance of atypical cells (PAP, x400); (d) The salt and pepper sign of chromatin pattern, pleomorphic nuclei with an atypical cell groups (PAP, x1000); (e) Cellular specimen staining positively for calcitonin with immunoperoxidase $(\times 200)$; $(f)$ Fibrovascular, fine hyaline stroma with solid and follicular pattern (HE, x200). 
avoid misdiagnosis in the presence of nuclear groove, expanded and hyper-chromasia. In their study, Canberk et al. [14] indicated reactive reparative changes in nucleus expanding, presence of fine chromatin, small nucleolus, suspicious grooves and pseudo inclusion-like nuclear hole and similar cytomorphologic characteristics are found hyperplastic lesions. LiVolsi's study [15] stated that abnormalities in benign lesions morphology were found in degenerative nodules, Graves' disease and nodular goitre although it is most often seen in Hashimoto's thyroiditis. Sometimes, inclusion and nuclear clarification were determined in nodular goitre tissue slides and these conditions were mistake for artefact, especially fixation artefacts by many pathologists. The helpful diagnostic clue in these cases is the diffuse nature of the pattern. Faquin et al. [16] defined in their retrospective study that abnormalities in nuclear morphology might be observed in benign lesions.

In our study, slides were seen as cellular patterns in follicular lesions and cytologically, there was not any colloid or a little colloid, with micro follicular pattern, clusters of single and double layers forming, slightly larger than the normal thyrocytes in coarse chromatin pattern and with round nucleus. Presence of suspicion of neoplasia in crowded three-dimensional patterns was remarkable (Figure 3). For follicular neoplasia, presence of each of trabecular, micro follicular and 3-dimensional crowded pattern are a combination of these is an important finding [5].

In follicular carcinoma, there were not any normal shaped follicles and macro-follicles. Micro-follicular structures in 3-dimension clusters. Tight 3-dimensional clusters, anizokaryozis, overlapping, dense droplet and small clusters of colloid were prominent cytological features (Figure 5E). Micro-follicles had 6-12 follicle cells. Observation of liquid colloid at the ground was thought to reflect limited macrofollicles. Stamataki et al. [6] study implied that structural architecture is important factor for evaluating of the cytologic diagnosis of follicular neoplasm and also stated existence of dense foamy large cytoplasm, anisocytosis and hypertrophic nucleolus were found to be determining factor for obtaining true diagnosis of Hurtle cell neoplasm on the TP smears.

In our study, cells were blue dense granular cytoplasm, large, polygonal shaped, enlarged round nucleus, central nucleus or macrofollicular nucleus in the Hurtle cell lesions. Nucleus frequently localized eccentric. There were plasmacytoid appearance of cells and discohesive clusters were present. There were not any colloid material or a little was found. We identified prominent oxyphilic thin foamy Hurtle cell accompanied with lymphocytes in Hashimoto's thyroiditis. Lymphoid cell reaction was determined in the ground. Lymphocytes were in small diameter, narrow-unclear cytoplasm, round granular chromatin pattern.

In our study, in PTC, slides were generally rich in cells. A 3-dimensional papillary pattern with a fibro vascular core was observed. Mono-layer irregular lining of clusters were often detected. In these clusters cells were disorganized, tightly crowded and overlapping. There were also cells with nuclear melding. Nuclei were oval, with round pattern and larger than normal follicular cells (Figures 5 and 6). A p value $<0.05$ was considered statistically significant for five parameters of malignant cases (nuclear groove/irregular nuclear membrane, nuclear overlap/crowding, nuclear enlargement, nuclear pseudo inclusion and pale/fine chromatin) (Table 3). Faquin et al. study [16], presence of crowded and expanded nucleus, nuclear groove, fine chromatin pattern and prominent nucleolus were accentuated in diagnosis of PTC. Suzuki et al. study [17] have detected an increase in collagenous stroma, naked capillaries and trabecular and hobnail pattern, a decrease in papillary pattern and tissue fragments, the presence of intercellular spaces, a disappearance of pale nuclei, convoluted nuclei, eosinophilia nucleoli and perinucleolar halo, and well-preserved cell shape with procedure of Sure Path liquid-based cytology in PTC. According to their study, convoluted nuclei might be a new clue of PTC. In concordance with some studies, such as Stamaki et al. [6], Canberk et al. [14], Kefeli et al. [18], our study revealed that nucleus of PTC appeared to be large, oval, hypochromic, with small eosinophilia nucleoli, nuclear groove and pseudo inclusion. Dark-staining, "sticky" colloid (chewing gum-like) also can be observed but this finding is non-specific [14].

In the study of Nishigami et al. [19], pseudo inclusions were identified in $1.2 \%$ and nuclear groove were in $5 \%$ of PTC. Nuclearto-cytoplasmic ratio were respectively measured as $0.342,0.568-0.891$, 0.901 in cytological diagnosed as benign, indeterminate and malignant groups [19]. Similarly Kefeli et al. study [16], PTC cells nuclear size were measured as double-fold in benign cell's nucleus.

In our study, there were slides of undifferentiated carcinoma with rich-cells and marked coarsening in nuclei (Figure 8). There was common necrosis on the ground without colloid. Clusters were dis-cohesive and loose disorganized. One by one cell was frequently observed. There were large, pleomorphic, irregular nuclear lining, coarse granular hyper chromatic chromatin pattern, marked nucleolus. Spindle-shaped morphologic cells like sarcoma were seen and giant cells were observed [20].

In our study, slides of MC had rich-cells and generally they showed distributions of isolated cells and loose syncytial clusters. Cells were plasmocytic appearing, with eccentric-located nucleus and there were binuclear patterns in some areas. Chromatin pattern was in "salt and pepper sign" distribution and in granular structure. In some of them, small nucleolus might be observed and there were no colloid (Figure 9). In concordance with the study of Canberk et al. [14], main findings were uniformly distributed cells, salt and pepper sign of chromatin, sporadically existence of amyloid on the ground, plasmocytoid, spindle, polygonal cells in TP smears from the medullary carcinoma. Presence of cellular structure in the aspirate is an important finding. There was no colloid. Nuclear pseudo inclusion is possible and bi/ multi-nucleation may also exist. Giant atypical cells can be observed. Cytoplasm is in medium density and thin granular-shape.

Consequently, in our study, we obtained TP-PAP stained slides with completely rich cells. Problems of inadequacy was exceeded by this study method, pathologists evaluated cyto-morphologic and histomorphologic findings of TP slides in every stage of aspiration [21]. It is well understood how important it is to obtain benign and malignant lesions with this method. Nuclear groove/irregular nuclear membrane, nuclear overlap/crowding, nuclear enlargement, nuclear pseudo inclusion and pale/fine chromatin were found statistically significant at PTC. This study showed that TP method is easy to use for thyroid fine needle aspiration biopsy.

\section{Acknowledgements}

We would like to thank the general surgery department of Hitit University Education and Research Hospital.

\section{References}

1. Mastorakis E, Meristoudis C, Margari N, Pouliakis A, Leventakos K, et al. (2014) Fine needle aspiration cytology of nodular thyroid lesions: A 2-year experience of the Bethesda system for reporting thyroid cytopathology in a large regional and a university hospital, with histological correlation. Cytopathology 25: 120-128.

2. Luu MH, Fischer AH, Pisharodi L, Owens CL (2011) Improved preoperative definitive diagnosis of papillary thyroid carcinoma in FNAs prepared with 
Citation: Baş Y, Keser HH, Erenler BH (2017) Cytomorphologic Evaluation of the Thin Prep for Fine Needle Aspiration of the Fresh Thyroidectomy Specimens. J Cytol Histol 8: 445. doi: 10.4172/2157-7099.1000445

both ThinPrep and conventional smears compared with FNAs prepared with ThinPrep alone. Cancer Cytopathology 119: 68-73.

3. Duncan LD, Forrest L, Law WM Jr, Hubbard E, Stewart LE (2011) Evaluation of thyroid fine-needle aspirations: Can ThinPrep be used exclusively to appropriately triage patients having a thyroid nodule? Diagn Cytopathology 39 : 341-348.

4. Rossi ED, Morassi F, Santeusanio G, Zannoni GF, Fadda G (2010) Thyroid fine needle aspiration cytology processed by ThinPrep: An additional slide decreased the number of inadequate results. Cytopathology 21: 97-102.

5. Cibas ES, Ali SZ (2009) The Bethesda System For Reporting Thyroid Cytopathology. Am J Clin Pathology 132: 658-665.

6. Stamataki M, Anninos D, Brountzos E, Georgoulakis J, Panayiotides J, et al. (2008) The role of liquid-based cytology in the investigation of thyroid lesions. Cytopathology 19: 11-8.

7. Penín ÁM, San Miguel FP, Seoane $\mathrm{Cl}$, Cunqueiro SR, Palmeiro CR, et al. (2013) Needle washing increases the diagnostic yield of fine needle aspiration biopsy of the thyroid gland. Endocrinol Nutr. 60: 115-118.

8. Michael CW, Pang Y, Pu RT, Hasteh F, Griffith KA (2007) Cellular adequacy for thyroid aspirates prepared by ThinPrep: How many cells are needed? Diagn Cytopathology 35: 792-797.

9. Kim Y, Choi KR, Chae MJ, Shin BK, Kim HK, et al. (2013) Stability of DNA, RNA cytomorphology, and immune-antigenicity in Residual ThinPrep Specimens. APMIS 121: 1064-1072.

10. Dyhdalo K, Macnamara S, Brainard J, Underwood D, Tubbs R, et al. (2014) Assessment of cellularity, genomic DNA yields, and technical platforms for BRAF mutational testing in thyroid fine-needle aspirate samples. Cancer Cytopathology 122: 114-122.

11. Saleh HA, Hammoud J, Zakaria R, Khan AZ (2000) Comparison of Thin-Prep and cell block preparation for the evaluation of Thyroid epithelial lesions on fine needle aspiration biopsy. Cytojournal 25: 3 .

12. Choi J, Shim HS, Song JW, Chae SW, Lee YN, et al. (2013) Image analysis of peripheral compression artefacts of ThinPrep liquid-based cytology preparations. Cytopathology 24: 99-104.

13. Zhu W, Michael CW (2007) How important is on-site adequacy assessment for thyroid FNA? An evaluation of 883 cases. Diagn Cytopathology 35: 183-186.

14. Canberk Ş, Fırat P, Schmitt F (2015) Pitfalls in the Cytological Assessment of Thyroid Nodules. Turkish J Pathology 31: 18-33.

15. LiVolsi VA (2011) Papillary thyroid carcinoma: An update. Mod Pathology 24: 1-9.

16. Faquin WC, Cibas ES, Renshaw AA (2005) A typical" Cells in Fine-Needle Aspiration Biopsy Specimens of Benign Thyroid Cysts. Cancer Cytopathology 105: 71-9.

17. Suzuki A, Hirokawa M, Higuchi M, Takada N, Yamao N, et al. (2016) Differentiating between benign follicular nodules and follicular neoplasms in thyroid liquid-based cytology preparations. Diagn Cytopathology 44: 659-64.

18. Kefeli M, Akpolat I, Yildirim A, Sunter AT, Kandemir B (2010) Morphometric analysis in cytologic evaluation of papillary thyroid carcinoma. Anal Quant Cytol Histology 32: 234-238.

19. Nishigami K, Liu Z, Taniguchi E, Koike E, Ozaki T, et al. (2012) Cytological features of well-differentiated tumors of uncertain malignant potential: Indeterminate cytology and WDT-UMP. Endocrine Journal 59: 483-487.

20. Ustun B, Chhieng D, Dyke AV, Carling T, Holt E, et al. (2014) Risk Stratification in Follicular Neoplasm, A Cytological Assessment Using the Modified Bethesda Classification. Cancer Cytopathology 122: 536-45.

21. Walts AE, Mirocha J, Bose S (2013) Follicular lesion of undetermined Significance in Thyroid FNA Revisited. Diagnostic Cytopathology 42: 18-22. 